BMJ Open Sport \& Exercise Medicine

\title{
Quantitative and qualitative analysis of head and body impacts in American 7v7 non-tackle football
}

\author{
Ron Jadischke, ${ }^{1}$ Jessica Zendler (D) , , ${ }^{1,2}$ Erik Lovis, ${ }^{1}$ Andrew Elliott, \\ Grant C Goulet ${ }^{1}$
}

To cite: Jadischke R, Zendler J, Lovis E, et al. Quantitative and qualitative analysis of head and body impacts in American $7 \mathrm{v} 7$ non-tackle football. BMJ Open Sport \& Exercise Medicine 2020;6:e000638. doi:10.1136/ bmjsem-2019-000638

- Additional material is published online only. To view please visit the journal online (http://dx.doi.org/10.1136/ bmjsem-2019-000638).

Accepted 6 December 2019

\section{Check for updates}

(c) Author(s) (or their employer(s)) 2020. Re-use permitted under CC BY-NC. No commercial re-use. See rights and permissions. Published by BMJ.

${ }^{1}$ Xenith, Detroit, Michigan, USA ${ }^{2}$ School of Kinesiology, University of Michigan, Ann Arbor, Michigan, USA

Correspondence to Dr Jessica Zendler; jzendler@xenith.com

\section{ABSTRACT}

Objectives Non-tackle American football is growing in popularity, and it has been proposed as a safer alternative for young athletes interested in American football. Little is known about the nature of head contact in the sport, which is necessary to inform the extent to which protective headgear is warranted. The objective of this study was to identify the location, types and frequency of head and body contacts in competitive 7v7 non-tackle American football. Methods Video analysis was used to document the type, frequency and mechanism of contacts across a series of under 12, under 14 and high school non-tackle tournament games. A subset of impacts was quantitatively analysed via 3-D model-based image matching to calculate the preimpact and postimpact speed of players' heads and the change in resultant translational and rotational velocities.

Results The incidence rate of head contact was found to be low (3.5 contacts per 1000 athlete-plays). Seventy-five per cent of head contacts were caused by a head-toground impact. No head-to-head contacts were identified. Most contacts occurred to the rear upper (occiput) or side upper (temporal/parietal) regions. Head-to-ground impact was associated with a maximum preimpact velocity of $5.9 \pm 2.2 \mathrm{~m} / \mathrm{s}$ and a change in velocity of $3.0 \pm 1.1 \mathrm{~m} / \mathrm{s}$. Conclusion Non-tackle football appears to represent a lower contact alternative to tackle football. The distribution of head impact locations, mechanisms and energies found in the present study is different than what has been previously reported for tackle football. The existing tackle football standards are not appropriate to be applied to the sport of non-tackle football, and sport-specific head protection and headgear certification standards must be determined.

\section{INTRODUCTION}

Non-tackle American football is growing in popularity, and it has been proposed as a safer alternative for young athletes interested in American football. ${ }^{1}$ The game is characterised by the replacement of the tackle with movements involving less contact, such as detaching a flag worn at the ball carrier's waist or touching the ball carrier with two hands below the neck, which has been suggested to reduce injury risk. Non-tackle leagues and governing bodies have begun to consider
What are the new findings?

- This is the first study to use qualitative and quantitative video analysis to evaluate head contact in youth non-tackle American football.

- Head contact in non-tackle American football is less frequent and less severe than American tackle football.

- Head contact typically occurs from contact with another player's body (but not head) or the ground and occurs to the rear or side of the head.

- Head protection should be designed specifically to non-tackle football, as the head impact profile is unique to other sports in which headgear is used such as American tackle football, international football or rugby.

the requirements for protective headgear. However, little is known about the nature and extent of head injuries in non-tackle football nor the location, frequency and magnitude of head impacts.

Head and face injuries in adult non-tackle football have been reported to account for $12 \%-55 \%$ of injuries. ${ }^{2-6}$ Concussion rates range from $2 \%$ to $23 \%$ of all injuries, ${ }^{236-8}$ with an incidence rate of 1.78 concussions per 1000 athlete exposures (AE, defined as one athlete participating in one game). ${ }^{3}$ Peterson $e t a l^{8}$ determined that youth flag football players experienced a concussion incidence of 1.33 per 1000 AEs, which was more than tackle football players in the same study, similar to rates reported for youth tackle players elsewhere ${ }^{9-12}$ and less than youth rugby athletes. ${ }^{13-17}$ Lynall and colleagues ${ }^{18}$ recorded 0.66 head impacts per $\mathrm{AE}$ in a cohort of youth flag football players using a headband-mounted impact sensor. This rate is lower than reported for the tackle football cohort in the study and in other studies. ${ }^{19-21}$ The location of impacts in these studies is unknown, and no video was taken to confirm the frequency of impacts, therefore, the frequency could be overestimated. 
The aim of this study was to expand current understanding of the location, types and frequency of head and body contacts in competitive $7 \mathrm{v} 7$ non-tackle American football. Video analysis was used to document the type, frequency and mechanism of contacts across a series of under 12 (12U), under 14 (14U) and high school (HS) non-tackle tournament games. Subsequently, a subset of impacts was quantitatively analysed via 3-D model-based image matching to calculate the preimpact and postimpact head speed to estimate impact severity $(\Delta \mathrm{V})$.

\section{METHODS}

\section{In-game video recording}

The study was designed after consulting with $7 \mathrm{v} 7$ coaches, players and parents about typical contact in the sport and their questions about player safety and appropriate protective equipment. Games were played by $12 \mathrm{U}, 14 \mathrm{U}$ and HS teams. The games took place between July 2018 and March 2019 at two sites: site 1, an outdoor American football field, and site 2, an indoor multipurpose playing field. Both of these sites had artificial turf. Qualitative impact data were collected at both sites but only data from site 1 were used for quantitative head impact reconstruction.

For site 1, the site was scanned with a 3-D colour laser scanner (LS120, Faro, USA). The laser scans were registered together using registration spheres and field markings in postprocessing to generate a 3-D point cloud of the stadium. This point cloud information was used for subsequent image calibration for head impact reconstruction. Fourteen stationary action cameras (Hero6, GoPro, USA) were mounted on tripods around the stadium such that any point on the field of play was within $30 \mathrm{~m}$ of at least two cameras. The cameras used $41^{\circ}$ field of view (FOV) lenses and recorded at $2.7 \mathrm{~K} / 120 \mathrm{fps}$ with a shutter speed of $1 / 1920 \mathrm{~s}$ and a white balance of 5000 $\mathrm{K}$. These parameters were selected following an internal validation study. ${ }^{22}$ For site 2 , fifteen cameras were magnet mounted on I-beams around the field of play. The site was indoors so the camera frame rate was reduced to $4 \mathrm{~K} / 60 \mathrm{fps}$ and used an automatic shutter speed to optimise the image exposure. At both sites an additional camera with a $120^{\circ}$ FOV GoPro Hero6 lens with $4 \mathrm{~K}$ resolution and 60 (site 1) or 30 (site 2) frame rate was placed to provide an overall view of the field. Camera times were synchronised via an external clock manually. There were two levels of synchronisation used. All cameras were first roughly synchronised to time of day using a clock. This synchronised the cameras to within approximately $1 \mathrm{~s}$. After an impact was identified for tracking, the video was analysed frame by frame to align videos from multiple cameras. This synchronisation procedure was done by aligning a discrete event in the video, such as a hand or foot touching the ground.

\section{Qualitative video analysis}

The video analysis methods were based on previous work to evaluate the nature and frequency of head impact in

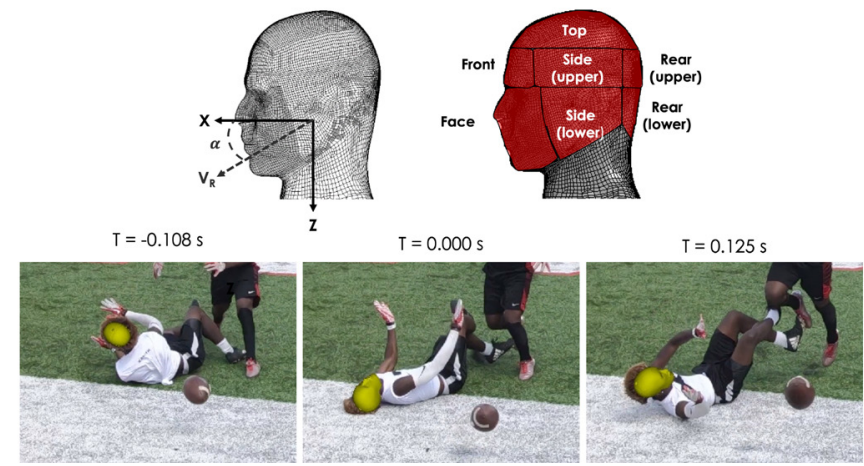

Figure 1 Methods for analysis of head impact. (Upper left) The head coordinate system (HCS) axes used to express local translations and rotations. Not shown is the y-axis, which points from the left to the right side of the head. Extension is represented as +ve rotation about the y-axis. $\alpha$ is defined as the angle of the resultant head velocity vector relative to the XY plane. (Upper right) Definition of head impact locations for in-game video analysis. (Lower) Example of head impact reconstruction using 3-D model-based image matching for a head-to-ground (H2G) impact. Three frames (before, at and after impact) from a single-camera view are shown. $\mathrm{T}=0.000 \mathrm{~s}$ denotes the head impact frame. Note that the athlete's hair has a large offset from the head and is moving throughout impact. Detail of the model-based image matching procedure for this example, including a second camera view, is provided in online supplementary material A.

contact sports. ${ }^{2324}$ The overall camera was reviewed to identify plays with contact, and the game number, play number, play type, time of day and the approximate location on the field where the play of interest occurred were documented. The location on the field referenced the yardage line and the lateral position on the field. The play type was documented as a short pass ( $0-10$ yards), medium pass (10-20 yards) or a long pass ( $>20$ yards). The distance of the pass was identified as the distance the football travelled in the air from the quarterback to reaching the receiver.

Based on the field location of the contact, the play of interest was identified in three $41^{\circ} \mathrm{FOV}$ camera views. A $3 \mathrm{~s}$ video clip was extracted to assess the type of impact and the location of impact on the head (figure 1). If multiple contacts occurred, they were separated into first contact, second contact and third contact. Type of impact was classified as: body to body (B2B), body to ground (B2G), head to body (H2B), head to ground (H2G) and head to head $(\mathrm{H} 2 \mathrm{H})$. A worked example is provided in online supplementary material A.

\section{Quantitative video analysis (head impact reconstruction)}

All plays involving head contact recorded at site 1 were targeted for video-based reconstruction of head kinematics at impact. Additionally, a set of plays in which offence and defensive players fell to the ground but no head contact occurred (B2G contact) were extracted for comparison. Model-based image matching was used to reconstruct head translational velocity $(\mathrm{V})$ and rotational 
velocity $(\omega)$ over time, similar to previously published methods. ${ }^{25}{ }^{26} \mathrm{In}$ a laboratory validation of our modelbased image matching implementation, we determined the mean absolute errors in the estimated change in resultant translational velocity and rotational velocity $\left(\Delta \mathrm{V}_{\mathrm{R}}\right.$ and $\Delta \omega_{\mathrm{R}}$, respectively) during simulated $\mathrm{H} 2 \mathrm{G}$ and $\mathrm{H} 2 \mathrm{H}$ impacts to be $\pm 0.24 \mathrm{~m} / \mathrm{s}( \pm 10.7 \%)$ and $\pm 3.4 \mathrm{rad} / \mathrm{s}$ $( \pm 21.8 \%)$, respectively. ${ }^{22}$

A worked example of the model-based image matching process is provided in online supplementary material A. For each impact, three separate camera views were identified and reviewed. The two primary (or best) views of the impact were used for reconstruction. Three-second video clips from the two primary views were extracted and uploaded into head tracking software (PFTrack, The Pixel Farm, UK) along with colour laser scan data of the stadium. Common points were selected in the video clips and laser scan data to align the camera views. Subsequently, the National Operating Committee on Standards for Athletic Equipment (NOCSAE) and Hybrid III headforms were fit to the head in both camera views in each video frame from approximately $150 \mathrm{~ms}$ preimpact to $150 \mathrm{~ms}$ postimpact or for 18 frames in the cases of no head impact (figure 1). Global head position, orientation and translational and rotational velocities were calculated from the positional tracking data. Transformation matrices were applied to transform the data to the local head coordinate system (HCS, figure 1). Rotational speed about the head $\mathrm{x}$-axis and $\mathrm{z}$-axis was reported as an absolute value, since biomechanically there would be no difference from a left/right z-axis rotation (ie, the motion that results in 'No') or a left/right x-axis rotation (ie, ear to shoulder motion). For the y-axis, flexion (-ve) and extension (+ve) were reported with their respective signs in place, because y-axis rotation can result in significantly different cervical spine kinematics. The positional and rotational data were verified by exporting them into CAD software (Polyworks, InnovMetric, Canada) while overlaying the laser scan data.

Several kinematical measures were calculated from the velocity data. The maximum preimpact translational velocity in the field coordinate system and in the $\mathrm{XY}$ plane (ie, field plane) were calculated as the maximal velocity in the $100 \mathrm{~ms}$ prior to impact or the maximal in cases with no head impact. The maximal rotational speed was reported as the maximal speed in the entire tracking sequence. The change in translational and rotational velocities due to impact ( $\Delta \mathrm{V}$ and $\Delta \omega$, respectively) were calculated by analysing the velocity curves and video to assess difference in speed between the time of contact and the end of contact. Contact was defined through frame-by-frame review of the video. $\Delta \mathrm{V}$ and $\Delta \omega$ were calculated along each axis, and the sum of the squares was taken to represent $\Delta \mathrm{V}_{\mathrm{R}}$ and $\Delta \omega_{\mathrm{R}}$. The angle of the head velocity vector relative to the XY plane in the HCS during the preimpact motion of the head was also calculated $(\alpha)$.

\section{RESULTS}

Quantitative video analysis

Total contact exposure

In total, 48 games and 1643 plays were recorded for video analysis (table 1 ). The majority of games were played by HS $(n=38)$, followed by $14 \mathrm{U}(\mathrm{n}=6)$ and $12 \mathrm{U}(\mathrm{n}=4)$. $12 \mathrm{U}$ and $14 \mathrm{U}$ games lasted $20 \mathrm{~min}$, while HS games lasted $25 \mathrm{~min}$, resulting in 19 hours and $10 \mathrm{~min}$ of game footage. Table 1 details the number of contact-plays, contacts per play and contact type by age group. Significant contact was identified in 252 plays $(15.3 \%)$, and $65.5 \%$ of contactplays had more than one contact on the play. In a few cases, two separate players were involved in contacts. The overall contact incidence rate was 19.8 per 1000 athleteplays.

\section{Contact type}

B2G and B2B were the most common contact types across all ages (figure 2). When the first contact was B2G, it typically involved a player falling to the ground after diving for a ball or tripping. When B2B was the first contact, the play was typically two players attempting to catch a pass resulting in B2B contact with one or both players falling to the ground subsequently. Second contacts were mostly B2G followed by H2G. Thirty-nine cases involved a third contact, which consisted of $28 \mathrm{H} 2 \mathrm{G}, 9 \mathrm{~B} 2 \mathrm{G}$ and $2 \mathrm{H} 2 \mathrm{~B}$. No $\mathrm{H} 2 \mathrm{H}$ contacts were identified. The small sample size for $12 \mathrm{U}$ and $14 \mathrm{U}$ precludes statistical analysis by age group. Qualitatively, the results were similar across age groups.

Table 1 Summary of game exposure and contact incidence by age

\begin{tabular}{|c|c|c|c|c|c|c|c|c|c|c|c|c|c|}
\hline \multirow[b]{2}{*}{$\begin{array}{l}\text { Age } \\
\text { group }\end{array}$} & \multicolumn{2}{|c|}{ Exposure } & \multicolumn{4}{|c|}{ All contacts } & \multicolumn{3}{|c|}{$\begin{array}{l}\text { Contacts on } \\
\text { play }\end{array}$} & \multicolumn{4}{|c|}{ Head contact } \\
\hline & Games & Plays & Plays & Contacts & $\begin{array}{l}\text { IR per } \\
1000 \text { AP }\end{array}$ & $\begin{array}{l}\text { IR per } \\
100 \mathrm{PH}\end{array}$ & 1 & 2 & 3 & Plays & Contacts & $\begin{array}{l}\text { IR per } \\
1000 \text { AP }\end{array}$ & $\begin{array}{l}\text { IR per } \\
100 \mathrm{PH}\end{array}$ \\
\hline $12 U$ & 4 & 126 & 16 & 27 & 15.3 & 145 & 7 & 7 & 2 & 4 & 4 & 2.3 & 21.4 \\
\hline $14 U$ & 6 & 198 & 34 & 63 & 22.7 & 225 & 8 & 23 & 3 & 9 & 9 & 3.3 & 32.1 \\
\hline
\end{tabular}

$\mathrm{AP}$, athlete-plays; HS, high school; IR, incidence rate; $\mathrm{PH}$, player-hours (computed assuming 20 min games for $12 \mathrm{U}$ and $14 \mathrm{U}$ and $25 \mathrm{~min}$ games for HS); 12U, under 12; 14U, under 14. 


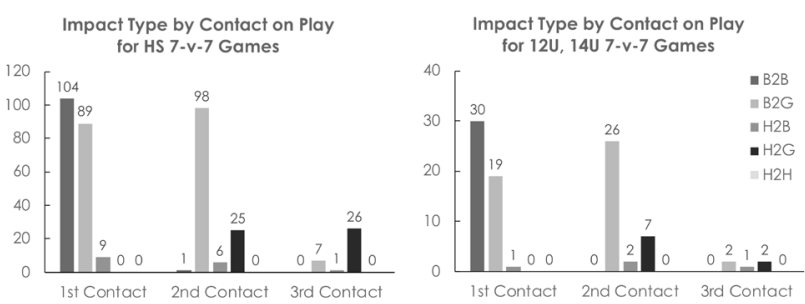

Figure 2 Distribution of contact types by first, second and third contacts of the play for high school (HS; left) and under 12-under 14 (12U-14U) combined (right). Head contacts typically occurred on the second or third contact of the impact play, and the majority were head to ground $(\mathrm{H} 2 \mathrm{G})$. No head-to-head $(\mathrm{H} 2 \mathrm{H})$ contacts were detected across the three age groups. B2B, body-to-body contact; B2G, body-toground contact; $\mathrm{H} 2 \mathrm{~B}$, head-to-body contact; $\mathrm{H} 2 \mathrm{G}$, head-toground contact; $\mathrm{H} 2 \mathrm{H}$, head-to-head contact.

\section{Head contact}

Head contact occurred on $4.8 \%$ of plays, resulting in a head contact incidence of 3.5 per 1000 athlete-plays (table 1). The majority of head contacts were H2G $(75.0 \%)$, followed by H2B (25.0\%). Head contacts typically occurred on the second or third contact of the impact play. For H2G, the majority of head contacts involved the rear upper head region (occiput) or the side upper head region (temporal/parietal) striking the ground and always occurred as the second or third contact. For H2B, impact locations were more distributed across the head but still favoured the side and rear locations (figure 3). Qualitatively, contact location on the head was similar in $12 \mathrm{U}$ and $14 \mathrm{U}$ compared with HS.

\section{Head impact reconstruction}

Eighteen plays were extracted for video reconstruction (H2G: 9, B2G: 4, running: 5). Online supplementary material B provides data for each examined impact.

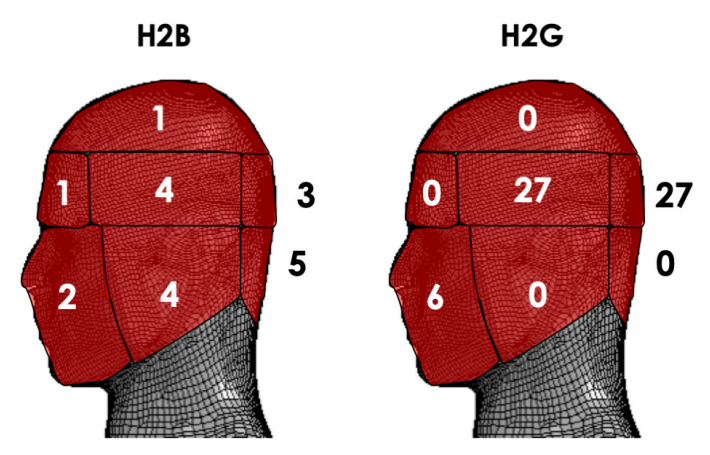

Figure 3 Distribution of head impact locations for headto-body (H2B) and head-to-ground (H2G) impacts. Values are summed across all recorded games. Trends were similar across age groups.
Across the 13 plays involving H2G and B2G impacts, the maximal preimpact velocity of the player's head in the ground (XY) plane was $5.0 \pm 1.8 \mathrm{~m} / \mathrm{s}$, with a downward vertical component of $3.7 \pm 1.0 \mathrm{~m} / \mathrm{s}$. Evaluating $\mathrm{H} 2 \mathrm{G}$ in isolation produced similar results, with a maximum preimpact velocity in the ground plane of $5.0 \pm 2.0 \mathrm{~m} / \mathrm{s}$ and a downward vertical component of $3.7 \pm 1.1 \mathrm{~m} / \mathrm{s}$ (table 2 ). The velocity vector of the head relative to the HCS XY plane $(\alpha)$ was calculated to be $-47.6 \pm 26.8^{\circ}$. Based on velocity of players running, the typical game speed was $7.4 \mathrm{~m} / \mathrm{s} \pm 1.2 \mathrm{~m} / \mathrm{s}$ in the ground plane. The head $\Delta \mathrm{V}_{\mathrm{R}}$ for $\mathrm{H} 2 \mathrm{G}$ cases was $3.0 \pm 1.1 \mathrm{~m} / \mathrm{s}$ with a median of $3.0 \mathrm{~m} / \mathrm{s}$ and a range of $1.5-4.9 \mathrm{~m} / \mathrm{s}$ over a $\Delta \mathrm{t}$ of approximately $0.06 \mathrm{~s}$ (table 3 ). The head $\Delta \omega_{\mathrm{R}}$ was $23.4 \mathrm{rad} / \mathrm{s} \pm 10.8 \mathrm{rad} / \mathrm{s}$ with a median of $21.8 \mathrm{rad} / \mathrm{s}$ and a range of $10.1-43.3 \mathrm{rad} / \mathrm{s}$.

\section{DISCUSSION}

This study reports the frequency, mechanism and magnitude of head and body contact in youth and HS 7v7 non-tackle football. Video analysis of 16100 player-hours of game footage indicated that contact frequency was relatively low at 19.8 contacts per 1000 athlete-plays, which supports the notion that non-tackle football represents a lower contact alternative to tackle football. Head impacts were found to be less common than body impacts. Head contacts typically involved contact of the rear or side of the head with the ground, although H2B contacts were noted as well. Preimpact head velocity for $\mathrm{H} 2 \mathrm{G}$ contacts was estimated to average $5.9 \mathrm{~m} / \mathrm{s}$ with an average $\Delta \mathrm{V}_{\mathrm{R}}$ of $3.0 \mathrm{~m} / \mathrm{s}$. To the authors' knowledge, these represent the first data of this type to be reported for non-tackle $7 \mathrm{v} 7$ football. Understanding the nature of head and body impacts is critical to developing appropriate measures for ensuring athlete safety in the sport and also to inform the development of protective equipment standards.

\section{Head contact incidence}

Overall the frequency of head contact reported herein is lower than the rates for youth tackle football, even accounting for the longer duration of tackle football games. $^{20} 27-29$ Differences in impact-recording methodology and definition of AE preclude direct comparison, particularly since sensor-based impact counts tend to overestimate impacts compared with video analysis. ${ }^{24} 3031$ However, conservative estimates would suggest approximately two head impacts per player per 10 gameminutes ${ }^{2029}$ compared with 0.1 head impacts per player per 10 game-minutes for non-tackle in the present study. Head contact incidence in $7 \mathrm{v} 7$ non-tackle appears to be less than non-helmeted contact sports, such as rugby, Australian Rules Football (ARF) and international football. Conservative estimates for participants in these sports suggest $0.2-0.7$ head impacts per player per 10 game-minutes. ${ }^{33-39}$

\section{Mechanism of head contact}

The mechanism of head impact was different from other contact sports. In international football, one of the most 
Table 2 Head velocities for $\mathrm{H} 2 \mathrm{G}$ and B2G impacts

\begin{tabular}{|c|c|c|c|c|c|c|c|c|}
\hline & \multicolumn{4}{|l|}{$H 2 G(n=9)$} & \multicolumn{4}{|l|}{ B2G $(n=4)$} \\
\hline & $v_{x y}(m / s)$ & $v_{z}(m / s)$ & $v_{R}(m / s)$ & $\omega_{\mathrm{R}}(\mathrm{rad} / \mathrm{s})$ & $v_{x y}(m / s)$ & $v_{z}(m / s)$ & $v_{R}(m / s)$ & $\omega_{\mathrm{R}}(\mathrm{rad} / \mathrm{s})$ \\
\hline Mean & 5.0 & 3.6 & 5.9 & 21.5 & 4.8 & 3.7 & 5.7 & 16.2 \\
\hline SD & 2.0 & 1.1 & 2.2 & 9.2 & 1.2 & 0.6 & 0.5 & 10.6 \\
\hline Range & $1.4-8.2$ & $1.7-4.8$ & $2.2-9.3$ & $11.4-37.0$ & $3.5-6.1$ & $2.9-4.2$ & $5.2-6.2$ & $8.3-31.2$ \\
\hline
\end{tabular}

B2G, body-to-ground impact; $H 2 G$, head-to-ground impact; $\omega_{R}$, resultant rotational velocity; $V_{R}$, resultant translational velocity; $V_{x y}$ ' translational velocity in the field (horizontal) plane; $\mathrm{V}_{\mathrm{z}}$, downward translational velocity.

common sources of injurious head impacts was found to be another player's head, ${ }^{40}$ which has led to rule changes and the development of soft protective headgear. ${ }^{41} 42$ Likewise in rugby, $\mathrm{H} 2 \mathrm{H}$ and head-to-shoulder contact during tackle events were the most common sources of head injury. ${ }^{1315} 4344$ Similarly, reducing helmet-to-helmet contact in American tackle football has been a key target of injury prevention efforts until recently. ${ }^{23}{ }^{45}$ No H2H impacts were identified in this study.

The most common source of head contact was impact with the ground, typically in a multicontact sequence of $\mathrm{B} 2 \mathrm{G}-\mathrm{H} 2 \mathrm{G}$ or B2B-B2G-H2G. The player first made contact with their body to the ground, and as their body decelerated on impact with the ground their head followed to make contact. Attempting to catch a pass was the most common scenario producing $\mathrm{H} 2 \mathrm{G}$, often with the defender and receiver making contact when challenging for the ball, causing a fall to the ground. H2B was another notable source of head impacts. Unlike H2G, several H2B contacts occurred on the first contact of the play. In most cases, as with $\mathrm{H} 2 \mathrm{G}$, the defender and the receiver were challenging in the air for a pass and collided.

\section{Head contact location}

The distribution of head impacts in non-tackle football favoured the side $(44 \%)$ and rear $(44 \%)$, with very few to the front $(1 \%)$, face $(10 \%)$ or top $(1 \%)$. In contrast, tackle football players experience the highest percentage of impacts to the front of the head (33\%-52\%), followed by smaller and relatively even distribution across the rear $(18 \%-40 \%)$, side $(13 \%-19 \%)$ and top $(10 \%-15 \%) .{ }^{2746-48}$ Rugby and ARF players have been found to experience a

Table 3 Change in translational and rotational head velocities due to $\mathrm{H} 2 \mathrm{G}$ impacts in the HS age group

\begin{tabular}{lllll}
\hline & $\Delta \mathbf{V}_{\mathrm{R}}(\mathrm{m} / \mathbf{s})$ & $\Delta \omega_{\mathrm{R}}(\mathrm{rad} / \mathbf{s})$ & $\boldsymbol{\alpha}\left({ }^{\circ}\right)$ & $\Delta \mathbf{t}_{\text {window }}(\mathbf{s})$ \\
\hline Mean & 3.0 & 23.4 & -47.6 & 0.06 \\
SD & 1.1 & 10.8 & 26.8 & 0.02 \\
Range & $1.5-4.9$ & $10.1-43.3$ & -79.6 to 0.2 & $0.04-0.10$ \\
\hline
\end{tabular}

$\alpha\left({ }^{\circ}\right)$, direction of head translational velocity vector with respect to the horizontal, (-) indicates the vector points below the horizontal; H2G, head-to-ground impact; HS, high school; $\Delta \omega_{R}$, change in resultant rotational velocity due to impact; $\Delta \mathrm{t}_{\text {window }}$, impact interval; $\Delta \mathrm{V}_{\mathrm{R}}$, change in resultant translational velocity due to impact. relatively heavier distribution to the front of the head and a lower distribution to the rear of the head than $7 \mathrm{v} 7 .^{3349}$ After excluding headers, international football players experience more front and top of head hits and fewer rear of head impacts than $7 \mathrm{v} 7 .{ }^{50}$ The discrepancy in head impact distribution is likely due to the unique nature of each sport. Whereas the other football disciplines involve tackling, which is associated with high percentage of head impacts, 7v7 does not involve tackling, and instead, head impact results from colliding with another player's body or falling to the ground when attempting to catch a pass. The unique distribution of head impacts in nontackle football highlights the need for sport-specific head protection and likewise sport-specific headgear certification standards. For example, these data indicate a certification standard designed for American tackle football would not be applicable to non-tackle $7 \mathrm{v} 7$ football.

\section{Head impact speed and energy}

Head velocities during nine H2G impacts and four B2G impacts were estimated with model-based image matching. ${ }^{25}{ }^{26}$ Our internal validation study determined similar errors to previous work. ${ }^{265152}$ For H2G impacts, maximum preimpact translational and rotational head velocities averaged $5.9 \pm 2.2 \mathrm{~m} / \mathrm{s}$ and $21.5 \pm 9.2 \mathrm{rad} / \mathrm{s}$, respectively. Kent et al. ${ }^{53}$ reported higher $\mathrm{V}_{\mathrm{R}}$ (mean: 8.3 $\mathrm{m} / \mathrm{s})$ and lower $\omega_{\mathrm{R}}($ mean: $13.5 \mathrm{rad} / \mathrm{s})$ for H2G impacts associated with concussion in professional American Football (National Football League, NFL). The direction of the velocity vector (mean: $-41.2^{\circ}$ ) was similar to the H2G impacts in the present study. Similarly, Pellman and colleagues $^{51}$ reported higher head impact closing velocities for NFL head impacts resulting in head injury as well as non-injurious impacts. In international football, head contusions resulting from $\mathrm{H} 2 \mathrm{H}$ impacts were associated with closing speeds of $1.3-2.5 \mathrm{~m} / \mathrm{s}$, while head injuries from elbow-to-head game impacts occurred at speeds ranging from 1.0 to $5.3 \mathrm{~m} / \mathrm{s}(3.0 \pm 1.7 \mathrm{~m} / \mathrm{s}){ }^{52}$ Examining $\Delta \mathrm{V}_{\mathrm{R}}$, the $7 \mathrm{v} 7 \mathrm{H} 2 \mathrm{G}$ impacts were associated with a $\Delta \mathrm{V}_{\mathrm{R}}$ similar to the one non-injurious NFL H2G impact $(2.9 \mathrm{~m} / \mathrm{s})$ and notably less than injurious head impacts. ${ }^{5153}$ In contrast, $\Delta \omega_{\mathrm{R}}$ was similar between the NFL injurious head impacts and the head impacts recorded in the current study. This raises the question of whether, by itself, $\Delta \omega_{R}$ is a biomechanical predictor of injury as there were no head injuries noted on these plays. 


\section{Limitations}

The study is limited by the relatively small sample size, particularly for $12 \mathrm{U}$ and $14 \mathrm{U}$ players, which precluded statistical comparisons across age groups. This study was not designed to evaluate injury epidemiology, and the majority of head contacts evaluated in this study were not associated with injury. At site 1 there were no injuries that required medical attention to our knowledge. At site 2, we observed two definitive injuries (clavicle fracture and a lower limb injury) and two instances where a player struck their head (one H2G, one H2B) and appeared shaken but returned to play on the next set. The lack of $\mathrm{H} 2 \mathrm{H}$ contacts and the relatively low-peak impact severities $\left(\Delta \mathrm{V}_{\mathrm{R}}\right)$ would suggest that non-tackle football incurs a lower risk of head injury compared with other contact sports, confirming prior epidemiological studies. $^{3} 68$ However, future work should incorporate systematic medical reporting to identify the risk of head injury and the associated injurious head biomechanics.

\section{CONCLUSIONS}

This study has summarised the frequency, magnitude and locations of head impacts in $18 \mathrm{U} 7 \mathrm{v} 7$ non-tackle football. To the authors' knowledge, these represent the first data of this type to be reported for non-tackle $7 \mathrm{v} 7$ football. Quantification of the nature of head and body impacts is critical to developing appropriate measures for ensuring athlete safety in the sport and also to inform the development of protective equipment standards. Non-tackle football appears to represent a lower contact alternative to tackle football with a unique distribution of head impact location, mechanism and energies. Head impacts were found to be infrequent and involved contact of the rear or side of the head with the ground or another player's body. No H2H impacts were identified. Taken together, these findings indicate that existing tackle football and soccer headgear standards are not appropriate to be applied to the sport of non-tackle football. Sport-specific head protection and headgear certification standards are necessary. Future work to inform these standards should include a detailed epidemiological understanding of the types of injuries that occur, the rate at which they occur compared with similar sports, and continued work in understanding the location, frequency and magnitude of these head contacts in non-tackle football, as set out in this present research.

Acknowledgements The authors acknowledge McCarthy Engineering, Mr Brian Gilbert and Mr Cole Tofflemire for their work in the head tracking analysis; the Pro Football Hall of Fame (Canton, $\mathrm{OH}$ ) for the use of their field; and the Legacy Center (Brighton, Ml) for their continued support in this research project.

Contributors AE, GCG and RJ were responsible for study conception and design. $\mathrm{RJ}$ and EL were responsible for data collection and analysis. All authors were responsible for data interpretation, manuscript development, critical review and final approval.

Funding The study was funded by Xenith, a manufacturer of helmets, gear and apparel for American football and related sports.

Competing interests $A E, G C G, R J$ and EL are employed by Xenith. JZ is a paid scientific advisor for Xenith.

\section{Patient consent for publication Not required.}

Provenance and peer review Not commissioned; externally peer reviewed.

Data availability statement Data are available upon reasonable request. Deidentified video analysis data by play (contact, contact type, location on field, play type, age group, location on head of impact, description of play) that underlie the results reported in this article are available upon reasonable request. Data will be available beginning 3 months after publication and ending 36 months following publication to researchers who provide a methodologically sound proposal for reuse in achieving the aims of this proposal. Proposals should be directed to jzendler@xenith.com.

Open access This is an open access article distributed in accordance with the Creative Commons Attribution Non Commercial (CC BY-NC 4.0) license, which permits others to distribute, remix, adapt, build upon this work non-commercially, and license their derivative works on different terms, provided the original work is properly cited, appropriate credit is given, any changes made indicated, and the use is non-commercial. See: http://creativecommons.org/licenses/by-nc/4.0/.

\section{ORCID iD}

Jessica Zendler http://orcid.org/0000-0003-4295-9917

\section{REFERENCES}

1 The Aspen Institute. What if... flag becomes the standard way of playing football until high school? 2018.

2 Burnham BR, Copley GB, Shim MJ, et al. Mechanisms of flagfootball injuries reported to the $\mathrm{HQ}$ air force safety center a 10-year descriptive study, 1993-2002. Am J Prev Med 2010;38:S141-7.

3 Kraus JF, Anderson BD, Mueller CE. An investigation of the effectiveness of a new helmet to control touch football head injuries. Am J Public Health Nations Health 1970;60:903-12.

4 Kraus JF, Gullen WH. An epidemiologic investigation of predictor variables associated with intramural touch football injuries. $\mathrm{Am} \mathrm{J}$ Public Health Nations Health 1969;59:2144-56.

5 McCarroll JR, Riddle R. Touch football: a friendly game? Phys Sportsmed 1980;8:93-7.

6 Kaplan Y, Myklebust G, Nyska M, et al. The epidemiology of injuries in contact flag football. Clin J Sport Med 2013;23:39-44.

7 Hisaka LI, Krahenbuhl GS. Intramural flag-football injuries on Tartan turf and natural grass. Proc Inst Mech Eng P 1976;3:296-300.

8 Peterson AR, Kruse AJ, Meester SM, et al. Youth football injuries: a prospective cohort. Orthop J Sports Med 2017;5:232596711668678.

9 Nation AD, Nelson NG, Yard EE, et al. Football-Related injuries among 6- to 17-Year-Olds treated in US emergency departments, 1990-2007. Clin Pediatr 2011;50:200-7.

10 Stuart MJ, Morrey MA, Smith AM, et al. Injuries in youth football: a prospective observational cohort analysis among players aged 9 to 13 years. Mayo Clin Proc 2002;77:317-22.

11 Turbeville SD, Cowan LD, Asal NR, et al. Risk factors for injury in middle school football players. Am J Sports Med 2003;31:276-81.

12 Harmon KG, Clugston JR, Dec K, et al. American medical Society for sports medicine position statement on concussion in sport. $\mathrm{Br} J$ Sports Med 2019;53:213-25.

13 Barden C, Stokes K. Epidemiology of injury in elite English Schoolboy rugby Union: a 3-year study comparing different competitions. J Athl Train 2018;53:514-20.

14 Leung FT, Franettovich Smith MM, Brown M, et al. Epidemiology of injuries in Australian school level rugby Union. J Sci Med Sport 2017;20:740-4.

15 Leung FT, Franettovich Smith MM, Hides JA. Injuries in Australian school-level rugby Union. J Sports Sci 2017;35:2088-92.

16 Sewry N, Verhagen E, Lambert M, et al. Seasonal time-loss match injury rates and burden in South African under-16 rugby teams. J Sci Med Sport 2019;22:54-8.

17 Pfister T, Pfister K, Hagel B, et al. The incidence of concussion in youth sports: a systematic review and meta-analysis. $\mathrm{Br} J$ Sports Med 2016;50:292-7.

18 Lynall RC, Lempke LB, Johnson RS, et al. A comparison of youth flag and tackle football head impact biomechanics. J Neurotrauma 2019;36:1752-7.

19 Campolettano ET, Gellner RA, Rowson S. High-magnitude head impact exposure in youth football. J Neurosurg Pediatr 2017;20:604-12.

20 Barber Foss K, DiCesare C, Diekfuss J, et al. Evaluation of head impact exposure between one season of youth versus high school football. JSMAHS 2018;4:1-3.

21 Daniel RW, Rowson S, Duma SM. Head impact exposure in youth football: middle school ages 12-14 years. J Biomech Eng 2014;136:094501-6. 
22 Jadischke R, Zendler J, Lovis E, et al. Development of a methodology and preliminary analysis of head impacts in American 7-v-7 non-tackle football. Proceedings of the IRCOBI ConferenceFlorence, 2019:615-6.

23 Lessley DJ, Kent RW, Funk JR, et al. Video analysis of reported concussion events in the National football League during the 2015-2016 and 2016-2017 seasons. Am J Sports Med 2018;46:3502-10.

24 Press JN, Rowson S. Quantifying head impact exposure in collegiate women's soccer. Clin J Sport Med 2017;27:104-10.

25 Bailey A, Funk J, Lessley D, et al. Validation of a videogrammetry technique for analysing American football helmet kinematics. Sports Biomech 2018:1-23.

26 Tierney GJ, Joodaki H, Krosshaug T, et al. Assessment of modelbased image-matching for future reconstruction of unhelmeted sport head impact kinematics. Sports Biomech 2018;17:33-47.

27 Cobb BR, Urban JE, Davenport EM, et al. Head Impact Exposure in Youth Football: Elementary School Ages 9-12 Years and the Effect of Practice Structure. Ann Biomed Eng 2013;41:2463-73.

28 Rose SC, Yeates KO, Fuerst DR, et al. Head impact burden and change in neurocognitive function during a season of youth football. $J$ Head Trauma Rehab 2019;34:87-95.

29 Broglio SP, Eckner JT, Martini D, et al. Cumulative head impact burden in high school football. J Neurotrauma 2011;28:2069-78.

30 Patton DA. A review of instrumented equipment to investigate head impacts in sport. Appl Bionics Biomech 2016;2016:1-16.

31 Kuo C, Wu L, Loza J, et al. Comparison of video-based and sensor-based head impact exposure. PLoS One 2018;13:e0199238.

32 Urban JE, Kelley ME, Espeland MA, et al. In-Season variations in head impact exposure among youth football players. J Neurotrauma 2019;36:275-81

33 King D, Hume P, Gissane C, et al. Head impacts in a junior rugby League team measured with a wireless head impact sensor: an exploratory analysis. J Neurosurg 2017;19:13-23.

34 King D, Hume PA, Brughelli M, et al. Instrumented Mouthguard acceleration analyses for head impacts in amateur rugby union players over a season of matches. Am J Sports Med 2015;43:614-24.

35 King DA, Hume PA, Gissane C, et al. Similar head impact acceleration measured using instrumented ear patches in a junior rugby Union team during matches in comparison with other sports. $J$ Neurosurg 2016;18:65-72.

36 Hecimovich M, King D, Dempsey A, et al. Head impact exposure in junior and adult Australian football players. J Sports Med 2018;2018:1-8.

37 McCuen E, Svaldi D, Breedlove K, et al. Collegiate women's soccer players suffer greater cumulative head impacts than their high school counterparts. J Biomech 2015;48:3720-3.
38 Chrisman SPD, Mac Donald CL, Friedman S, et al. Head impact exposure during a weekend youth soccer tournament. J Child Neurol 2016;31:971-8.

39 Chrisman SPD, Ebel BE, Stein E, et al. Head impact exposure in youth soccer and variation by age and sex. Clin J Sport Med 2019;29:3-10.

40 Andersen TE, Arnason A, Engebretsen L, et al. Mechanisms of head injuries in elite football. Br J Sports Med 2004;38:690-6.

41 Patton DA, Mclntosh AS. Considerations for the performance requirements and technical specifications of soft-shell padded headgear. Proc Inst Mech Eng P J Sport Eng Technol 2016;230:29-42.

42 Whyte T, Stuart CA, Mallory A, et al. A review of impact testing methods for headgear in sports: considerations for improved prevention of head injury through research and standards. $J$ Biomech Eng 2019;141:070803-86.

43 Fuller CW, Taylor A, Raftery M. Eight-season epidemiological study of injuries in men's international Under-20 rugby tournaments. $J$ Sports Sci 2018;36:1776-83.

44 Fuller CW, Taylor A, Kemp SPT, et al. Rugby world cup 2015: world rugby injury surveillance study. Br J Sports Med 2017;51:51-7.

45 Pellman EJ, Viano DC, National Football League's Committee on Mild Traumatic Brain Injury. Concussion in professional football: summary of the research conducted by the National football League's Committee on mild traumatic brain injury. Neurosurg Focus 2006;21:E12.

46 Munce TA, Dorman JC, Thompson PA, et al. Head impact exposure and neurologic function of youth football players. Med Sci Sports Exerc 2015;47:1567-76.

47 Young TJ, Daniel RW, Rowson S, et al. Head impact exposure in youth football: elementary school ages 7-8 years and the effect of returning players. Clin J Sport Med 2014;24:416-21.

48 Urban JE, Davenport EM, Golman AJ, et al. Head impact exposure in youth football: high school ages 14 to 18 years and cumulative impact analysis. Ann Biomed Eng 2013;41:2474-87.

49 Hecimovich M, King D, Dempsey A, et al. Youth Australian footballers experience similar impact forces to the head as Juniorand Senior-League players: a prospective study of kinematic measurements. J Sports Sci Med 2018;17:547-56.

50 Hanlon EM, Bir CA. Real-Time head acceleration measurement in girls' youth soccer. Med Sci Sports Exerc 2012;44:1102-8.

51 Pellman EJ, Viano DC, Tucker AM, et al. Concussion in professional football: reconstruction of game impacts and injuries. Neurosurgery 2003;53:799-814. discussion 812-4.

52 Withnall C. Biomechanical investigation of head impacts in football. Br J Sports Med 2005;39:i49-57.

53 Kent R, Forman J, Bailey AM, et al. The biomechanics of concussive helmet-to-ground impacts in the National Football League. $J$ Biomech 2020;99:109551. 